\title{
Study on the Effect of Air Throttling on Flame Stabilization of an Ethylene Fueled Scramjet Combustor
}

\author{
Ye Tian, Shunhua Yang, and Jialing Le \\ Science and Technology on Scramjet Laboratory, Hypervelocity Aerodynamics Institute of CARDC, Sichuan, Mianyang 621000, China \\ Correspondence should be addressed to Ye Tian; tianye@cardc.cn
}

Received 10 April 2015; Accepted 26 August 2015

Academic Editor: Hui Hu

Copyright (C) 2015 Ye Tian et al. This is an open access article distributed under the Creative Commons Attribution License, which permits unrestricted use, distribution, and reproduction in any medium, provided the original work is properly cited.

\begin{abstract}
The effect of air throttling on flame stabilization of an ethylene fueled scramjet combustor was investigated by numerical simulation and experiments in this paper. The results were obtained under the inflow condition with Mach number of 2.0, total temperature of $900 \mathrm{~K}$, total pressure of $0.8 \mathrm{MPa}$, and total equivalence ratio of 0.5 . The shock train generated by air throttling had a big effect on the flow structure of the scramjet combustor. Compared with the combustor without air throttling, the flow field with air throttling had a lower velocity and higher pressure, temperature, and vortices intensity. Air throttling was an effective way to achieve flame stabilization; the combustion in the combustor without air throttling was nearly blowout. In the experiment, the combustion was nearly blowout with air throttling location of $745 \mathrm{~mm}$, and the fuel/air mixture in the combustor with air throttling location of $875 \mathrm{~mm}$ was burned intensively. It was important to choose the location and time sequence of air throttling for fuel ignition and flame stabilization. The numerical simulation results agreed well with experimental measurements.
\end{abstract}

\section{Introduction}

When the flight Mach number is bigger than 6, the air flow remains completely supersonic throughout the scramjet combustor in a few milliseconds. Ignition and flame stabilization have been a serious concern in the design of scramjet engines due to the difficulties to anchor flames in a high-speed environment. Air throttling was an effective method to achieve ignition and combustion establishment. A proper shock train is generated by air throttling, and then the velocity decreases and the pressure increases in the combustor section which can effectively enhance the ignition and flame stabilization. An experiment using air throttling to initiate combustion in a scramjet combustor was studied by Mathur et al. [1]. When the air throttling was removed after the flame establishment, the shock train was retained leading to sustained combustion if sufficient heat release was produced in the combustor. Conversely, insufficient heat release might result in an unstable shock train and causes flame blowout. Control and optimization of ignition transient and flame development in a scramjet engine using air throttling were studied by Li et al. [2], the locations and operation timing of air throttling and fuel injection on the engine start-up transient characteristics were examined systematically, and a dynamic optimization scheme based on the genetic algorithm (GA) was developed to maximize the performance of air throttling. The transient process of flow establishment and combustion process were studied for an ethylene fueled direct-connect dual mode scramjet combustor with air throttling by Choi et al. [3]. Air throttling was confirmed to be effective means of the ethylene ignition and combustion establishment. A series of experiments were conducted by Bao et al. [4] to study the ignition characteristic of a flush wall, liquid kerosene fueled scramjet combustor. Experiment results showed that successful ignition could be achieved by the air throttling method. Flow development, fuel/air mixing, ignition transient, and flame development in an ethylene fueled scramjet engine with air throttling were studied by Yang et al. $[5,6]$. Their research showed that air throttling could generate a precombustion shock train in the isolator, the resultant decrease in the flow velocity and increases in the temperature and pressure in the combustor section to improve the ignition characteristics and the flame stabilization process. The flame stabilization of an 


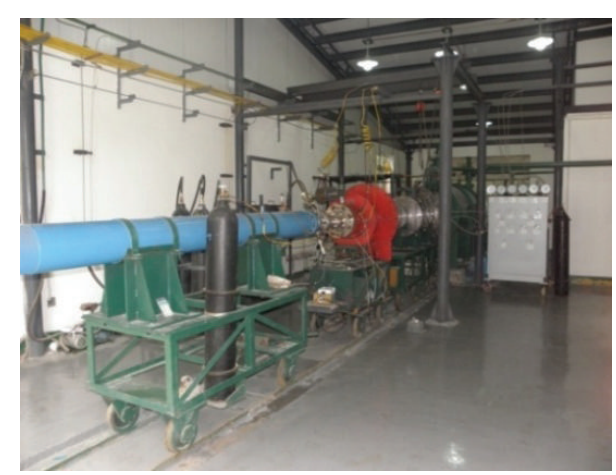

FIgUre 1: Photo of pulse combustion wind tunnel $[7,8]$.

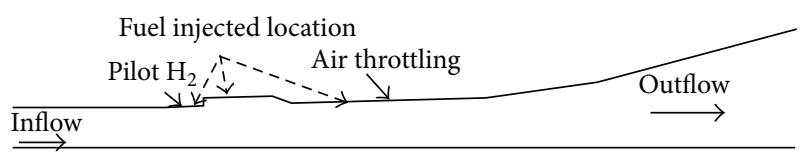

FIGURE 2: Schematic illustration of the scramjet.

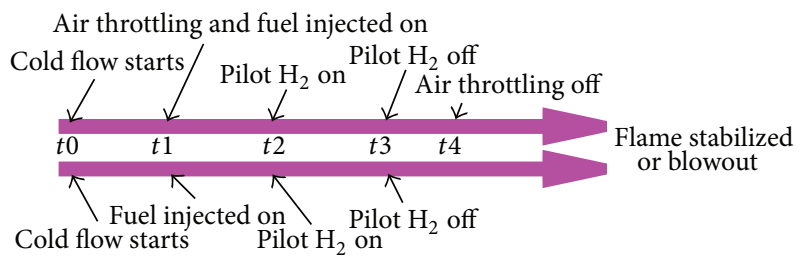

FIGURE 3: A schematic of the operation sequence of the system with and without air throttling.

ethylene fueled scramjet combustor with air throttling was investigated in this paper.

\section{Numerical Simulation and Experimental Methods}

2.1. Facility and Scramjet Configuration. The scramjet combustor was experimented in the China Aerodynamics Research and Development Center's (CARDC's) direct pulse combustion wind tunnel (Figure 1). A vitiated air heater was used to generate high enthalpy air flow supplied into the combustor. Oxygen was fed into the heater to obtain test gas with its mole fraction of oxygen being equal to that of standard air. Total temperature $\left(T_{t}\right)$ of the test gas was $900 \mathrm{~K}$ and total pressure $\left(P_{t}\right)$ was $0.8 \mathrm{MPa}$. The test gas was accelerated by the nozzle to Mach 2.0; the running time of the facility was about $400 \mathrm{~ms}$.

A schematic illustration of the combustor model was shown in Figure 2, the model consisted of an isolator and a combustor, the cross-sectional area was $50 \times 100 \mathrm{~mm}$ in the isolator, and the isolator length was $0.415 \mathrm{~m}$. The combustor length changed from $0.415 \mathrm{~m}$ to $1.7 \mathrm{~m}$; the combustor included a cavity (range: $0.415 \mathrm{~m} \sim 0.61 \mathrm{~m}$ ) and an expansion section (range: $0.61 \mathrm{~m} \sim 1.7 \mathrm{~m}$ ). The cavity depth was $10.8 \mathrm{~mm}$ and the cavity length was $195 \mathrm{~mm}$; the wall divergent angle

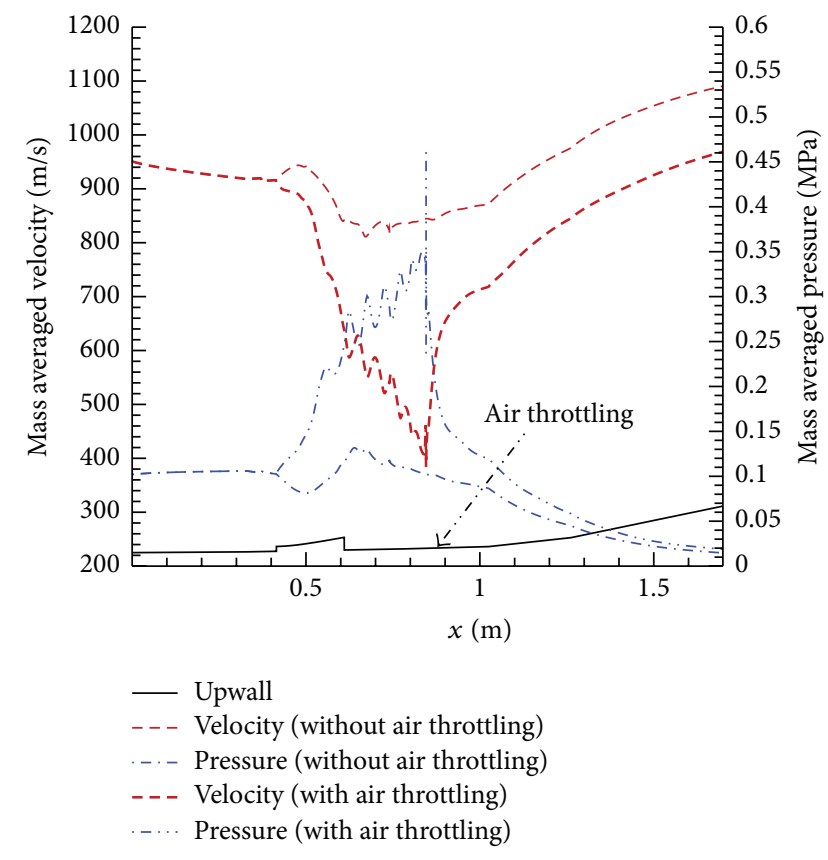

FIGURE 4: Mass averaged velocity and pressure of the scramjet combustor with and without air throttling.

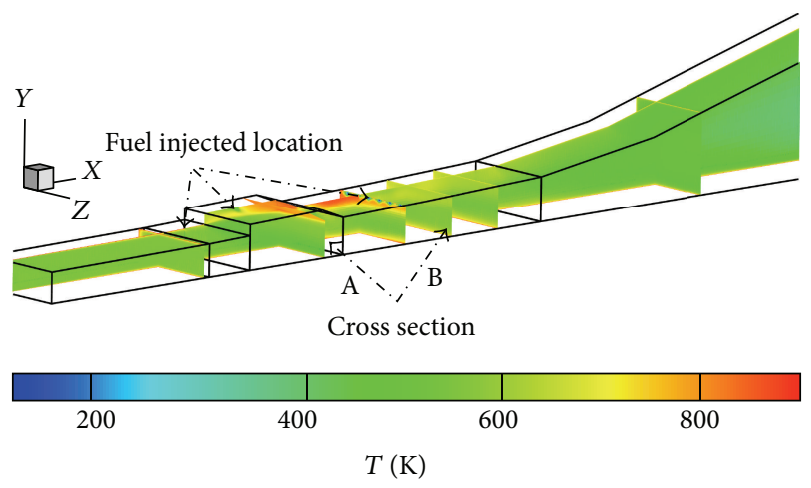

(a)

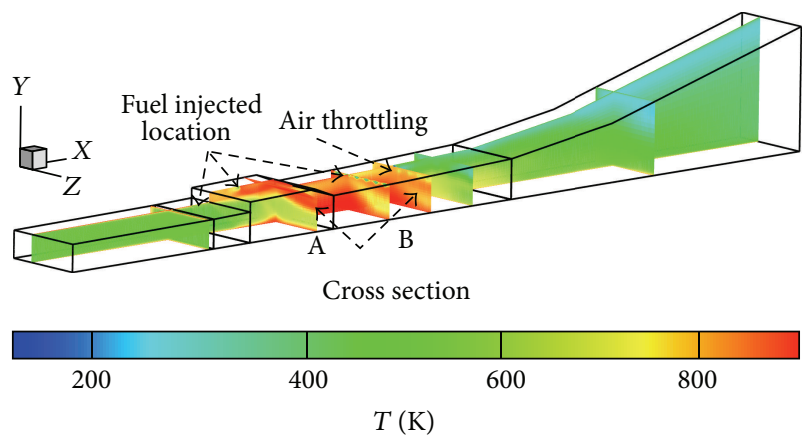

(b)

FIGURE 5: Static temperature contours of scramjet combustor with and without air throttling ((a) case without air throttling; (b) case with air throttling). 


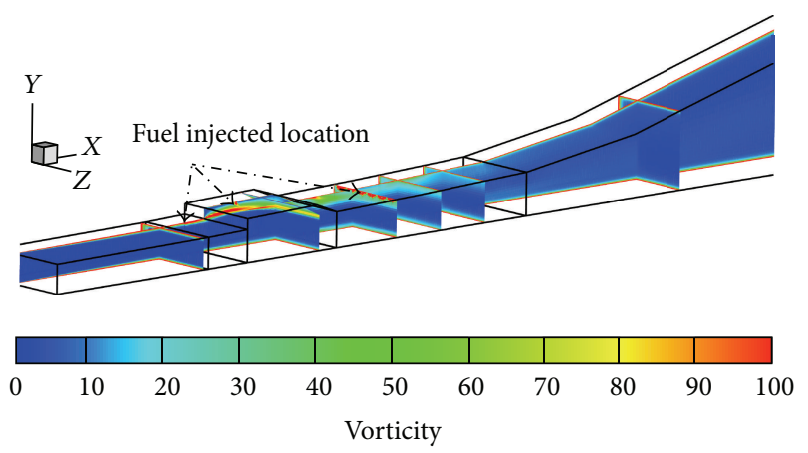

(a)

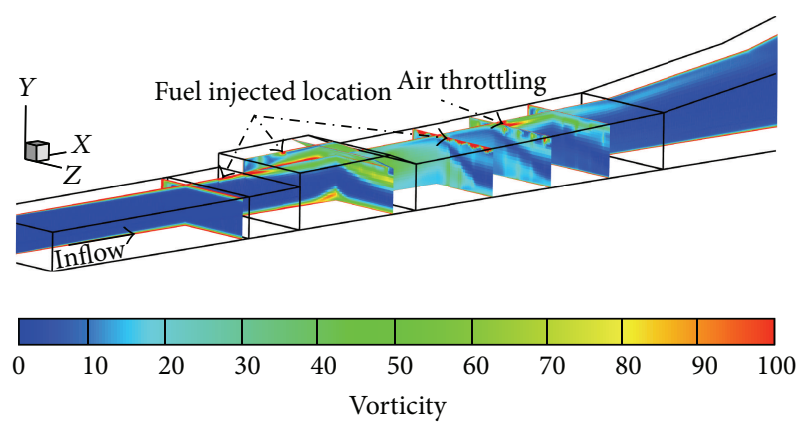

(b)

FIGURE 6: Vorticity magnitude contours of the scramjet combustor with and without air throttling ((a) case without air throttling; (b) case with air throttling).

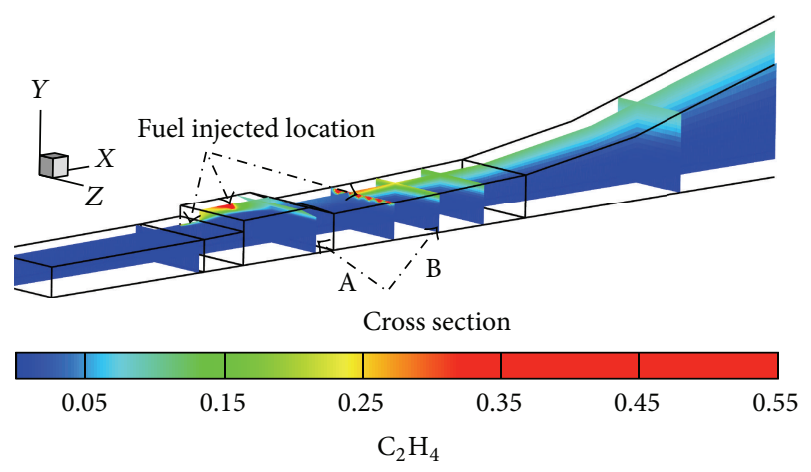

(a)

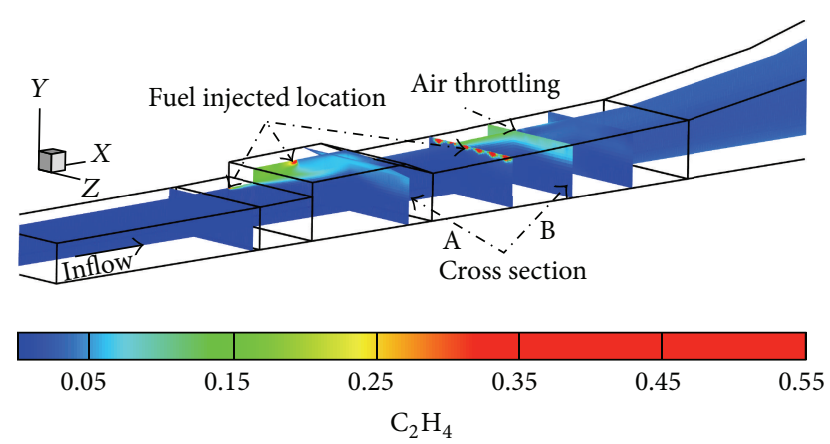

(b)

FIGURE 7: Fuel (ethylene) mass fraction of the scramjet combustor with and without air throttling ((a) case without air throttling; (b) case with air throttling).

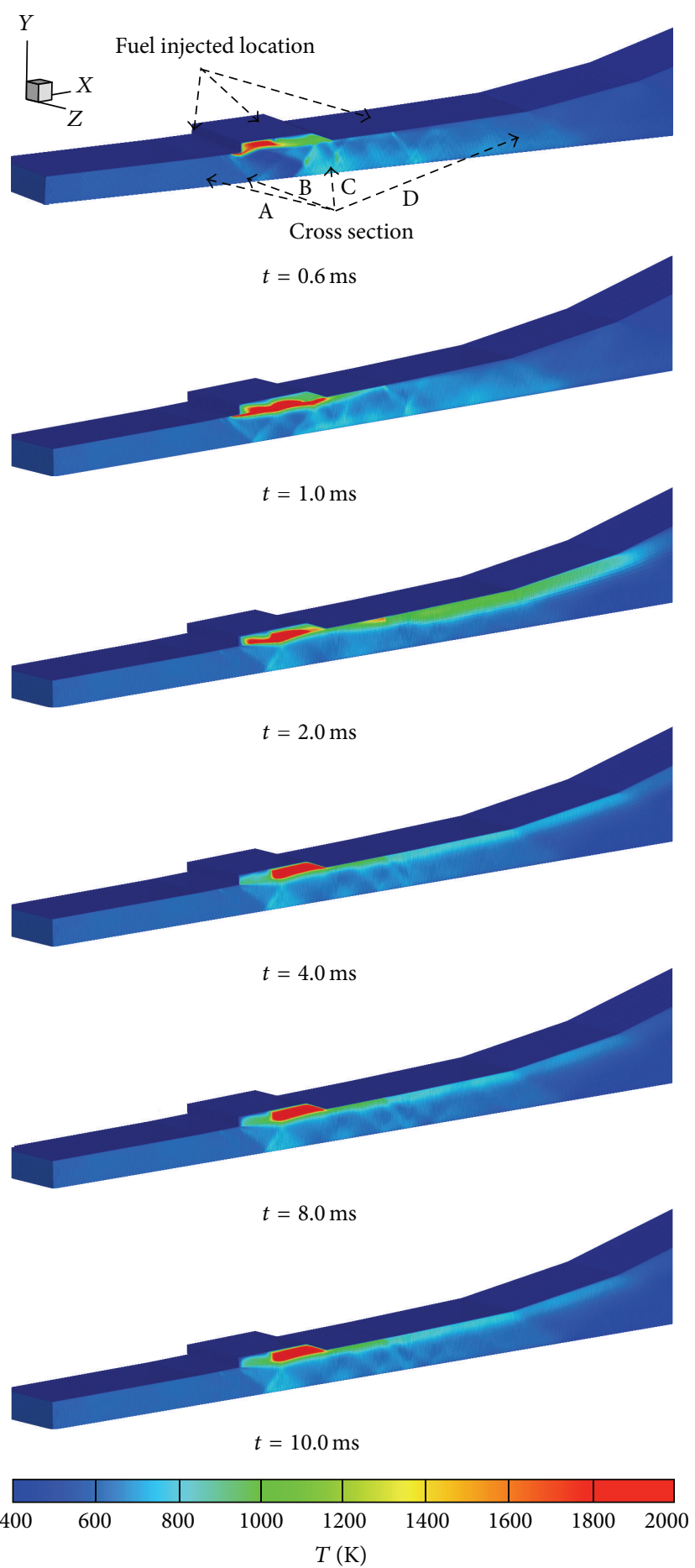

FIgURE 8: Evolution of the temperature field in the scramjet combustor during the ignition transient without air throttling.

was $1.4^{\circ}$. The expansion section contained four parts: the first part was from $0.61 \mathrm{~m}$ to $0.785 \mathrm{~m}$, the wall divergent angle was $1.4^{\circ}$, the second part was from $0.785 \mathrm{~m}$ to $1.026 \mathrm{~m}$, the wall divergent angle was $2.0^{\circ}$, the third part was from $1.026 \mathrm{~m}$ to $1.262 \mathrm{~m}$, the wall divergent angle was $8.0^{\circ}$, the last part was from $1.262 \mathrm{~m}$ to $1.7 \mathrm{~m}$, and the wall divergent angle was $15.0^{\circ}$. There were three fuel injected locations (K1: $390 \mathrm{~mm}$, 

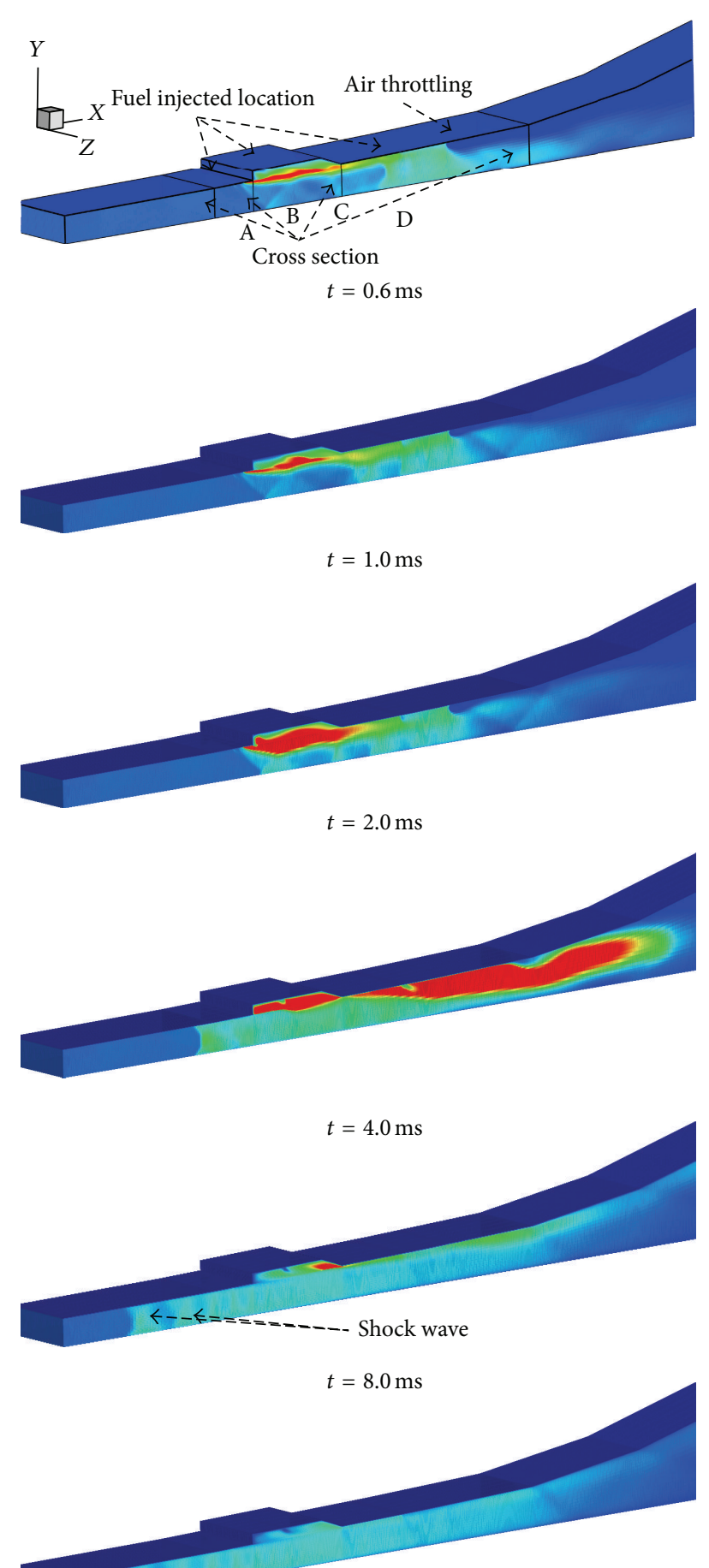

$t=10.0 \mathrm{~ms}$

$\begin{array}{cccccccc}400 & 600 & 800 & 1000 \quad 1200 & 1400 & 1600 & 1800 & 2000 \\ T(\mathrm{~K}) & \end{array}$

FIGURE 9: Evolution of the temperature field in the scramjet combustor during the ignition transient without air throttling. 
K2: $485 \mathrm{~mm}$, and $\mathrm{K} 3: 745 \mathrm{~mm}$ form the scramjet entrance) shown in Figure 2. The fuel which was directly injected into the air flow from the combustor wall was ethylene, the equivalence ratio of $\mathrm{K} 1$ was 0.1 , and the equivalence ratios of $\mathrm{K} 2$ and $\mathrm{K} 3$ were both 0.2 . There were 10 fuel injection holes $(3 \mathrm{~mm}$ in diameter and $6.4 \mathrm{~mm}$ interval in spanwise direction) at each injection. Pilot $\mathrm{H}_{2}$ located at $370 \mathrm{~mm}$ from the scramjet entrance was used for ignition. The location of the air throttling in the scramjet combustor was $745 \mathrm{~mm}$ or $875 \mathrm{~mm}$; the mass flux of air throttling was 30 percent of the inflow air. Wall pressure distribution was measured along the flow direction by pressure transducers (range: $0 \sim 700 \mathrm{kPa}$ ); the sampling frequency of pressure transducer was $1 \mathrm{kHz}$. Photos of the flow structure were taken by high-speed digital camera; flow structure images were taken with a frequency of 5000 fps.

2.2. Numerical Methods. In this study, the in-house CFD code AHL3D software was used for computation. The CFD code and its physical and chemical models had already been validated in $[9,10]$. A fully coupled form of species conservation equations and Reynolds averaged Navier-Stokes equations were used as a governing equation set for a chemically reacting supersonic viscous flow. The governing equations expressed in conservative vector form in the Cartesian coordinate system are

$$
\frac{\partial Q}{\partial t}+\frac{\partial F}{\partial x}+\frac{\partial G}{\partial y}+\frac{\partial E}{\partial z}=\frac{\partial F_{v}}{\partial x}+\frac{\partial G_{v}}{\partial y}+\frac{\partial E_{v}}{\partial z}+S .
$$

Here, $Q=\left(\rho, \rho u, \rho v, \rho w, \rho E_{t}, \rho C_{i}\right)^{T}$ and $C_{i}$ was the mass concentration for species $i$. $E_{t}$ was the total energy, including kinetic energy and internal energy. $E, F$, and $G$ were the inviscid fluxes; $F_{v}, G_{v}$, and $E_{v}$ were the viscid fluxes. $S$ was the source term; $u, v$, and $w$ were the velocity components in Cartesian coordinates $(x, y, z)$. $\rho$ was the density.

Cell-averaged finite volume techniques were used to solve the conservative form governing equations. LU-SGS method was used in time-marching. In space terms difference, thirdorder MUSCL interpolation method and AUSMPW+ scheme were used in inviscid fluxes construction; central difference method was used in viscous fluxes. Kok's modified $k-\omega$ TNT 2 -equation turbulence mode was used in turbulence simulations. The dual-time stepping method was used in unsteady numerical simulation and the real time step was $1 \times 10^{-7} \mathrm{~s}$. The ethylene reaction mechanism involved 3 elementary reaction steps and 7 reaction species as mentioned in [11].

2.3. Operation Sequence. A schematic of the operation sequence of the system with and without air throttling was shown in Figure 3. The operation started with the delivery of air flow through the entire system at the time of $t 0$. Once a steady flow was established, the fuel injectors and air throttling were turned on at the time of $t 1$. After a short period, the pilot $\mathrm{H}_{2}$ was injected into the air flow at the time of $t 2$. Ignition then occurred in the combustor, and the pilot $\mathrm{H}_{2}$ was off at the time of $t 3$. The air throttling was turned off after the flame was stabilized at the time of $t 4$. The heat release and associated pressure rise in the combustor

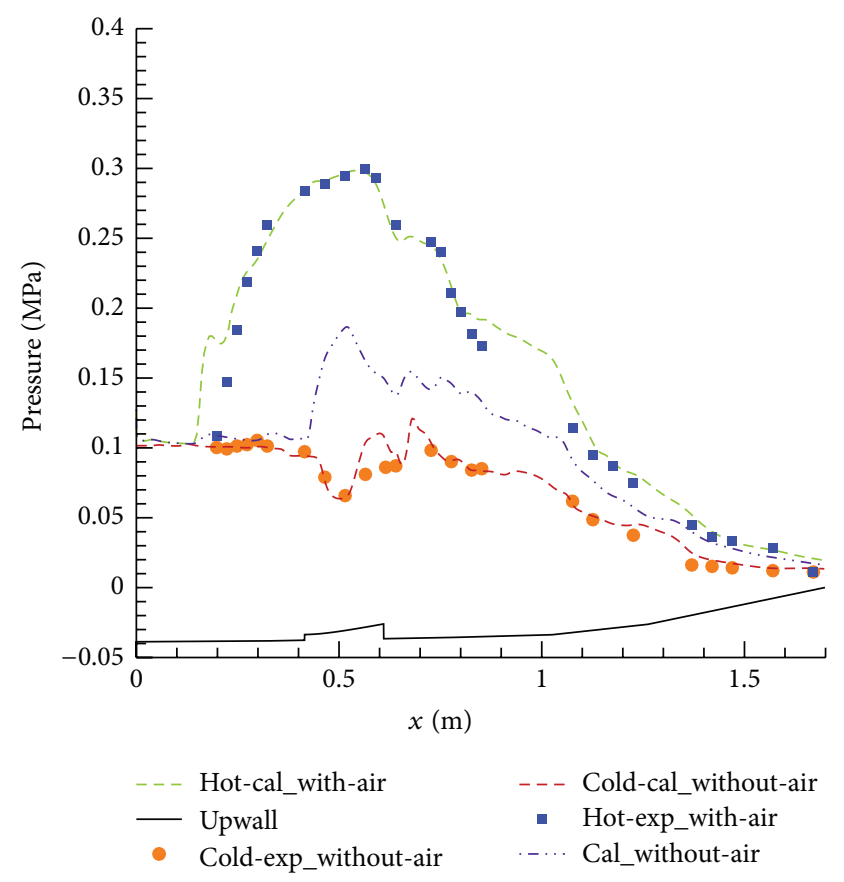

FIGURE 10: Wall pressure of the experiment and calculation with and without air throttling (hot-cal_with-air: calculation result of chemical reaction flow with air throttling; upwall: the up wall of the scramjet combustor; cold-exp_without-air: experimental result of nonreaction flow without air throttling; cold-cal_without-air: calculation result of nonreaction flow without air throttling; hotexp_with-air: experimental result of chemical reaction flow with air throttling; hot-cal_without-air: calculation result of chemical reaction flow without air throttling).

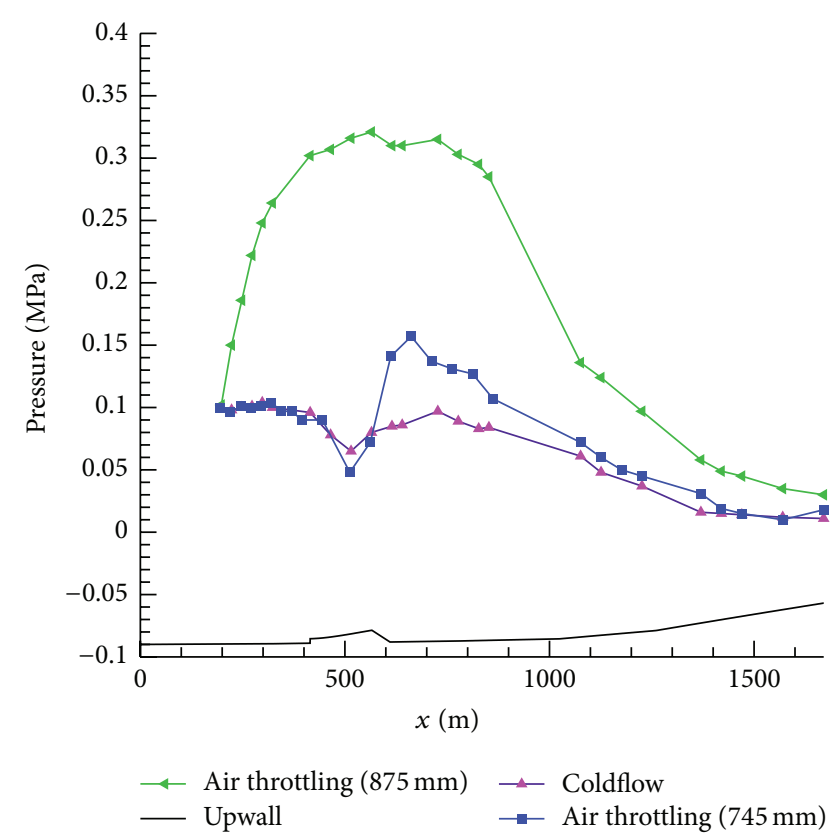

FIGURE 11: Wall pressure of the scramjet combustor with different air throttling location (air throttling $(875 \mathrm{~mm})$ : the location of the air throttling was $875 \mathrm{~mm}$ from the entrance of the combustor; air throttling $(745 \mathrm{~mm})$ : the location of the air throttling was $745 \mathrm{~mm}$ from the entrance of the combustor; coldflow: nonreacting flow of the scramjet combustor). 


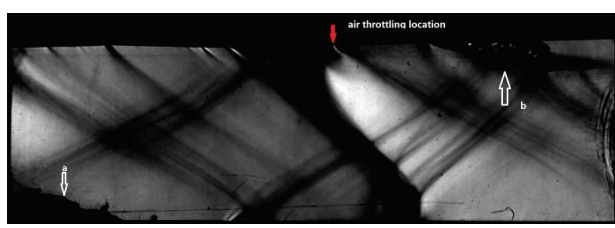

(a)
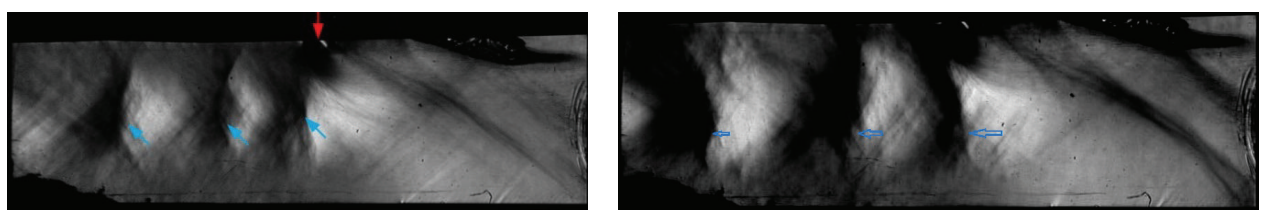

(c)

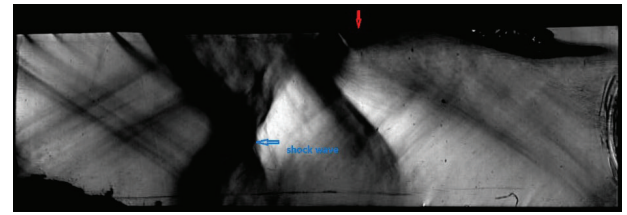

(b)

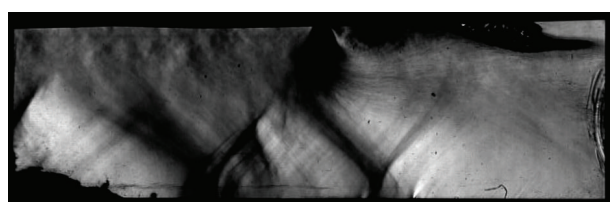

(e)

(d)

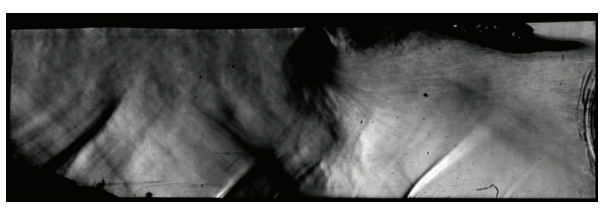

(f)

FIGURE 12: Schlieren graphs of the expansion region with air throttling at the location of $745 \mathrm{~mm}$ from the entrance of the combustor at different times $(\mathrm{a} \sim \mathrm{f})$.

retain the shock train required for sustaining combustion. Insufficient heat release leads to an unstable shock train and a premature removal of air throttling often resulted in flame blowout. It would spend much more time during the threedimensional unsteady numerical simulation, so the whole time of the numerical operation sequence was less than that in the experiment. In the numerical simulation, $t 0=-2.0 \mathrm{~ms}$, $t 1=-1.0 \mathrm{~ms}, t 2=0.0 \mathrm{~ms}, t 3=1.0 \mathrm{~ms}$, and $t 4=2.0 \mathrm{~ms}$ and the whole time of the operation sequence was $13.0 \mathrm{~ms}$. But in the experiment, $t 0=-20 \mathrm{~ms}, t 1=0.0 \mathrm{~ms}, t 2=70 \mathrm{~ms}$, $t 3=120 \mathrm{~ms}$, and $t 4=150 \mathrm{~ms}$.

\section{Results and Discussions}

3.1. Results of Nonreacting Flow. Mass averaged velocity and pressure of the scramjet combustor with and without air throttling were shown in Figure 4. The location of air throttling in the scramjet combustor was $875 \mathrm{~mm}$ from the entrance of the combustor. From the figure, we could see that the mass averaged velocity between the exit of the isolator and the front of the air throttling was about $400 \sim 600 \mathrm{~m} / \mathrm{s}$, which was much lower than that of the scramjet combustor without air throttling, which was about $800 \sim 900 \mathrm{~m} / \mathrm{s}$. The lower velocity of air flow in the scramjet combustor with air throttling resulted in a longer residence time for better fuel/air mixing. The mass averaged pressure of the scramjet combustor with air throttling was higher than that of the scramjet combustor without air throttling, which was helpful to ignition in the scramjet. Temperature contours of the scramjet combustor at different cross section were shown in Figure 5; the temperature of the scramjet combustor with air throttling was much higher than that of the scramjet without air throttling from the exit of the isolator, especially between cross sections " $A$ " and "B." The temperature of the scramjet with air throttling was higher than $700 \mathrm{~K}$ but that of the scramjet without air throttling was about $500 \mathrm{~K}$; the influencing zone of the shock train produced by air throttling in the scramjet combustor was from the exit of the isolator to the exit of the combustor. Thus it could be seen the thermodynamic parameters of the scramjet combustor flow field were influenced obviously by the shock train, especially between cross sections " $A$ " and "B." Compared with the case without air throttling, the flow field with air throttling had a lower velocity and higher pressure, temperature, and vortices intensity, which were helpful to ignite in the scramjet combustor.

Figure 6 presented the flow vortices in the combustor without air throttling (Figure 6(a)) and the case with air throttling (Figure 6(b)). Intense flow recirculation zones were formed downstream of the cavity due to the back pressure rise and separation of the boundary layer by air throttling. But that could not be seen from the scramjet combustor without 
air throttling in Figure 6(b). Isosurfaces of ethylene fuel mass fraction in the flow field without and with air throttling were shown in Figure 7. The depth of the fuel injected was small for the case without air throttling, this was because the velocity of the main flow was too high, so all the fuel of the scramjet without air throttling only existed in the boundary layer of the up wall, and there would not be any fuel into the main flow. The flow separation on the sidewalls lifted the shear layer from the cavity in the combustor with air throttling, which interacted with the shock train to induce large-scale vortices and flow distortion in the cavity, delivering more fuel/air mixture into the main flow. The shock-induced boundary layer separation on the sidewalls distorted the flow and spread the fuel toward the sidewalls and corners. As a result, we could see that the fuel occupied about one-third area of cross sections "A" and "B" in Figure 7, so fuel and air mixed better in the combustor with air throttling than that without air throttling.

3.2. Results of Reacting Flow. The spreading of flame in the scramjet combustor without air throttling was shown in Figure 8; the flame position was illustrated in terms of isosurfaces of temperature $T=2000 \mathrm{~K}$. Pilot $\mathrm{H}_{2}$ which was used for ignition was injected into the air flow upstream the fuel injected location. Figure 8 indicated that the ignition of the fuel/air mixture first occurs at $0.6 \mathrm{~ms}$ in the shear layer near the cavity front step in the combustor cavity, and then the flame propagated into the cavity ramp at the time of pilot $\mathrm{H}_{2}$ off $(t=1.0 \mathrm{~ms})$, but the flame was still in the shear layer. The flame propagated into the whole cavity at the time $t=$ $2.0 \mathrm{~ms}$. The flame was nearly blowout, only a small portion of the flame was anchored in the rearward of the cavity and in the boundary layer of the up wall after the time $t=4 \mathrm{~ms}$, and the flame had almost completely disappeared from the combustor at the end of the calculation $(t=10.0 \mathrm{~ms})$.

The spreading of flame in the scramjet combustor with air throttling was shown in Figure 9; the high temperature area of the scramjet combustor with air throttling was larger than that of the combustor without air throttling at any time. At the end of the calculation $(t=10.0 \mathrm{~ms})$ in Figure 9, the fuel/air mixture was still burned intensively in the whole cavity and near the wall, especially in the corner of the combustor and the shock train could be seen clearly in the isolator because of the pressure increased in the combustor.

Wall pressure of the experiment and calculation with and without air throttling was shown in Figure 10; we could see that the calculation results agreed well with the experiment results, so the numerical simulation data was credible. The combustion in the combustor without air throttling was nearly blowout, but the fuel/air mixture in the combustor with air throttling was burned intensively. So the wall pressure of reacting flow of the scramjet combustor with air throttling was higher than that of the combustor without air throttling, and the wall pressure of reacting flow of the scramjet combustor without air throttling was almost equal to that of the nonreacting flow of the combustor. From the
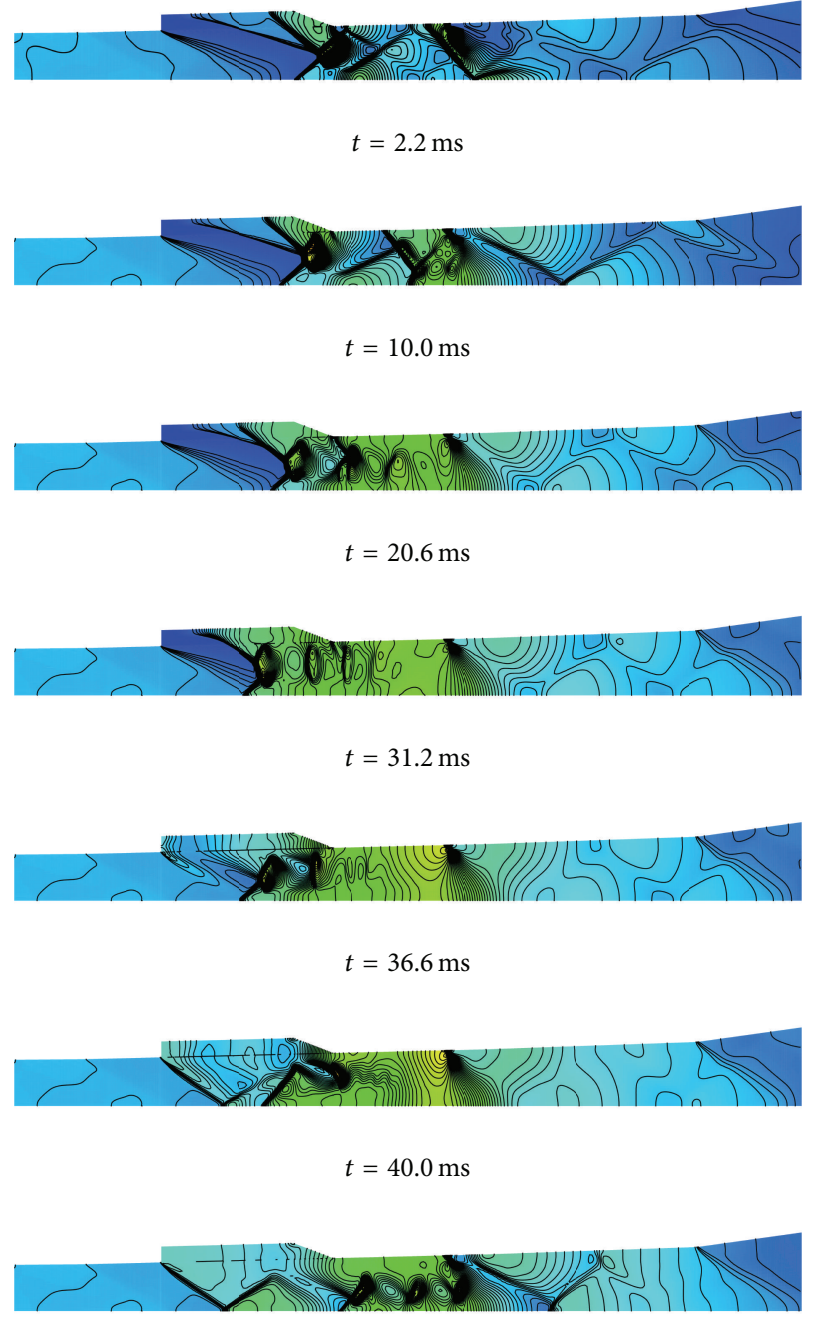

$t=55.0 \mathrm{~ms}$

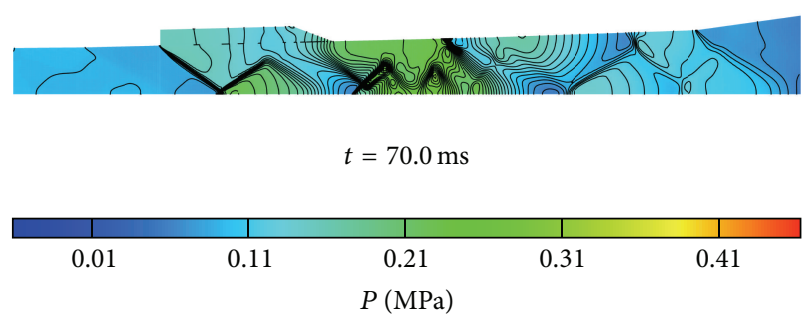

Figure 13: Pressure contours and iso-pressure lines of the scramjet combustor with air throttling at the location of $745 \mathrm{~mm}$ from the entrance of the combustor at different times.

above discussion, air throttling was an effective way to achieve flame stabilization in the scramjet combustor.

\subsection{Effects of the Location of Air Throttling on Flame Stabiliza-} tion. The wall pressure of the reacting flow in the scramjet combustor with different air throttling location $(875 \mathrm{~mm}$ and $745 \mathrm{~mm}$ ) was shown in Figure 11. The wall pressure of reacting flow along the combustor wall with air throttling located at $875 \mathrm{~mm}$ was much higher than that of the air 


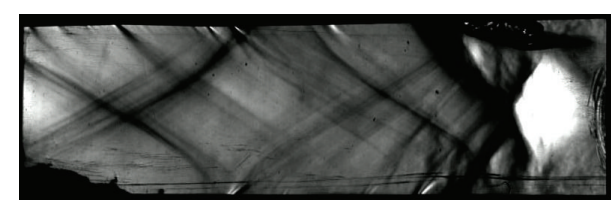

(a)

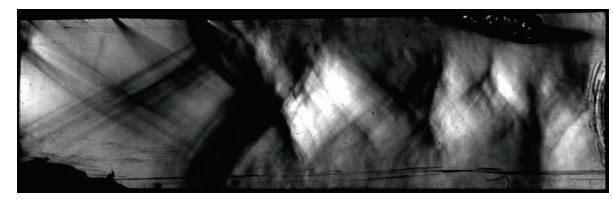

(c)

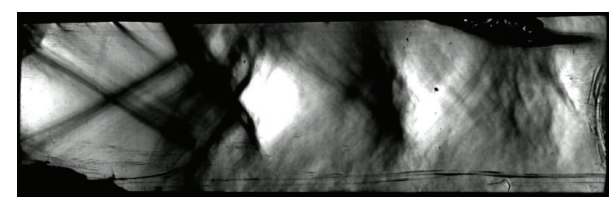

(e)

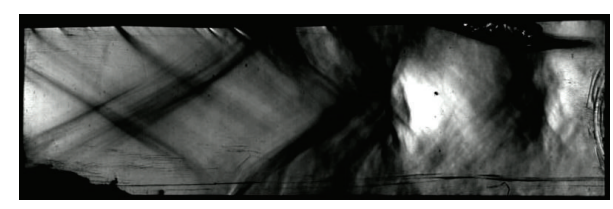

(b)

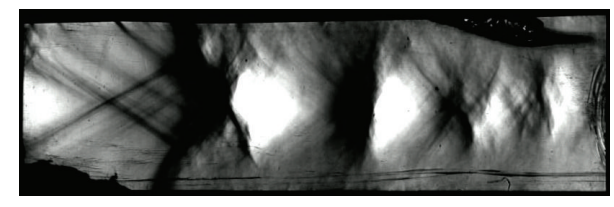

(d)

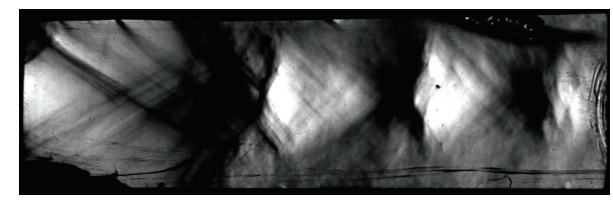

(f)

FIGURE 14: Schlieren graphs of the expansion region with air throttling at the location of $875 \mathrm{~mm}$ from the entrance of the combustor at different times $(\mathrm{a} \sim \mathrm{f})$.

throttling location of $745 \mathrm{~mm}$, and the wall pressure of the air throttling location of $745 \mathrm{~mm}$ was almost equal to that of the nonreacting case. The results indicated that the combustion was nearly blowout with the air throttling location of $745 \mathrm{~mm}$, and the fuel/air mixture in the combustor with the air throttling location of $875 \mathrm{~mm}$ was burned intensively.

In order to analyze the reason of the above experimental results, the flow structure in the scramjet combustor with different air throttling location was investigated by CFD and flow visualization. In the experiments, for all cases, the duration of the pilot $\mathrm{H}_{2}$ injection was from $70 \mathrm{~ms}$ to $120 \mathrm{~ms}$ and the duration of the air throttling was from $0 \mathrm{~ms}$ to $140 \mathrm{~ms}$. The duration of the experiment was over $400 \mathrm{~ms}$, it was impossible for CFD to simulate the whole test processes because the unsteady computation cost was too large to tolerate, and the CFD simulated time was about $70 \mathrm{~ms}$ for the present study, because we wanted to see the differences of the flow structure when the ignition started (pilot $\mathrm{H}_{2}$ injection started at $t=70.0 \mathrm{~ms}$ ). The cross section of the combustor was rectangle and the ratio of width to height is about 2 and the effect of the side wall on the flow structure was not great, so we used two-dimensional numerical simulation instead of three-dimensional computation.

The schlieren graphs in the expansion region with air throttling at the location of $745 \mathrm{~mm}$ at different times (a f) were shown in Figure 12. The visualized region of the flow field was taken from $610 \mathrm{~mm}$ to $830 \mathrm{~mm}$. Arrow points "a" and " $\mathrm{b}$ " in Figure 12(a) were a contamination and broken trail on the window. For the case of throttling at the location of $745 \mathrm{~mm}$, an oblique shock wave was firstly generated in front of the air throttling points when air throttling started as shown in Figure 12(a), then the oblique shock wave moved upstream and became " $\lambda$ " shock wave as shown in Figure 12(b), the " $\lambda$ " shock wave continued to move upstream and finally formed a shock train as shown in Figures 12(c) and $12(\mathrm{~d})$, but the length of the shock train became shorter in Figure 12(e), and the shock train disappeared at last in Figure 12(f). The numerical simulated flow structure with air throttling at the location of $745 \mathrm{~mm}$ was shown in Figure 13. There was an oblique shock wave near the location of air throttling at the time $t=2.2 \mathrm{~ms}$; then the wave moved upstream ( $t=10.0 \mathrm{~ms})$ and " $\lambda$ " shock wave was generated $(t=20.6 \mathrm{~ms})$. The pressure in the cavity rose up as the shock waves moved into the cavity; the expansion wave near the cavity front step became an oblique shock wave in order to match the increased pressure. The oblique shock wave reflected by the opposite wall, then the shock train moved backward and disappeared at the time $t=70.0 \mathrm{~ms}$, and finally there were some oblique shock waves instead of the original shock train in the flow field at this time.

The schlieren graphs in the expansion region with air throttling at the location of $875 \mathrm{~mm}$ at different times (a f) were shown in Figure 14. Compared with the case of air throttling at the location of $745 \mathrm{~mm}$, the shock wave train can sustain more time for this case, which can be concluded from Figures 14(f) and 12(f). In Figure 14(f), the shock train can sustain in the expanding section at $t=70.0 \mathrm{~ms}$, but in Figure 12(f), the shock train disappeared at $t=70.0 \mathrm{~ms}$. The numerical simulated flow structure with air throttling at the location of $875 \mathrm{~mm}$ was shown in Figure 15. The oblique shock wave was generated at $t=2.2 \mathrm{~ms}$ and then moved upstream, " $\lambda$ " shock wave was generated at $t=10.0 \mathrm{~ms}$, the shock wave continued to move forward and finally formed a shock train at $t=20.6 \mathrm{~ms}$, and the shock train lasted from $t=10.0 \mathrm{~ms}$ to $t=70.0 \mathrm{~ms}$. As time went on, the shock train disappeared at $t=80.0 \mathrm{~ms}$.

From the above analysis, it was important to choose the time for pilot $\mathrm{H}_{2}$ injection. When pilot $\mathrm{H}_{2}$ was injected into 

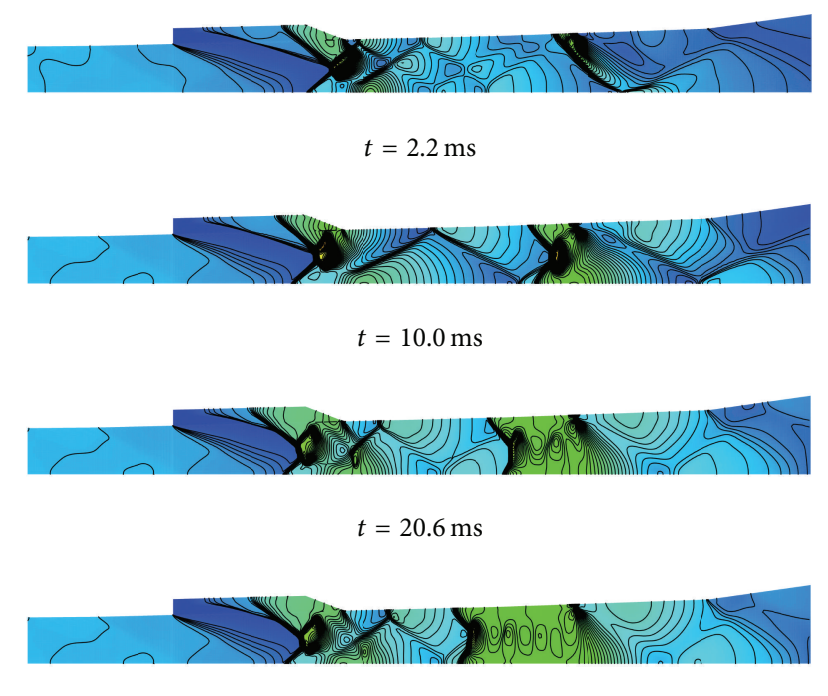

$t=31.2 \mathrm{~ms}$

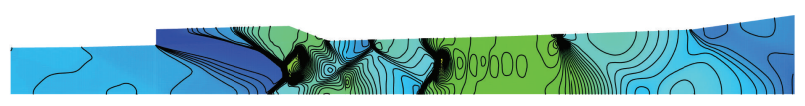

$t=36.6 \mathrm{~ms}$
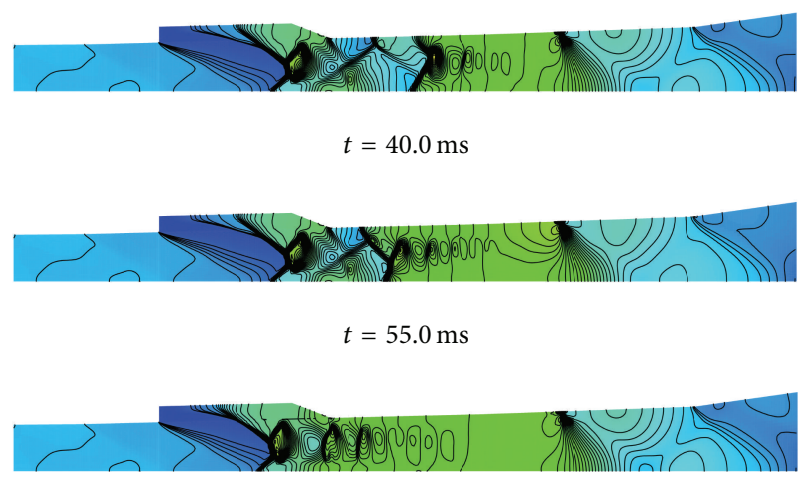

$t=70.0 \mathrm{~ms}$

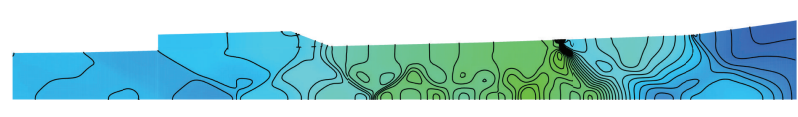

$t=80.0 \mathrm{~ms}$

Figure 15: Pressure contours and iso-pressure lines of the scramjet combustor with air throttling at the location of $875 \mathrm{~mm}$ from the entrance of the combustor at different times.

the flow field at $t=70.0 \mathrm{~ms}$, there were oblique shock waves in the flow field of the combustor with air throttling location of $745 \mathrm{~mm}$, but there was a shock train in the flow field of the combustor with air throttling location of $875 \mathrm{~mm}$. In order to further analyze the effect of the flow structure (oblique shock waves and shock train) on the ignition process, the thermodynamic parameters of the two flow fields were also investigated.

The wall pressure of the scramjet combustor with air throttling location of $745 \mathrm{~mm}$ and $875 \mathrm{~mm}$ at $t=70.0 \mathrm{~ms}$ was shown in Figure 16. The pressure of the case with air

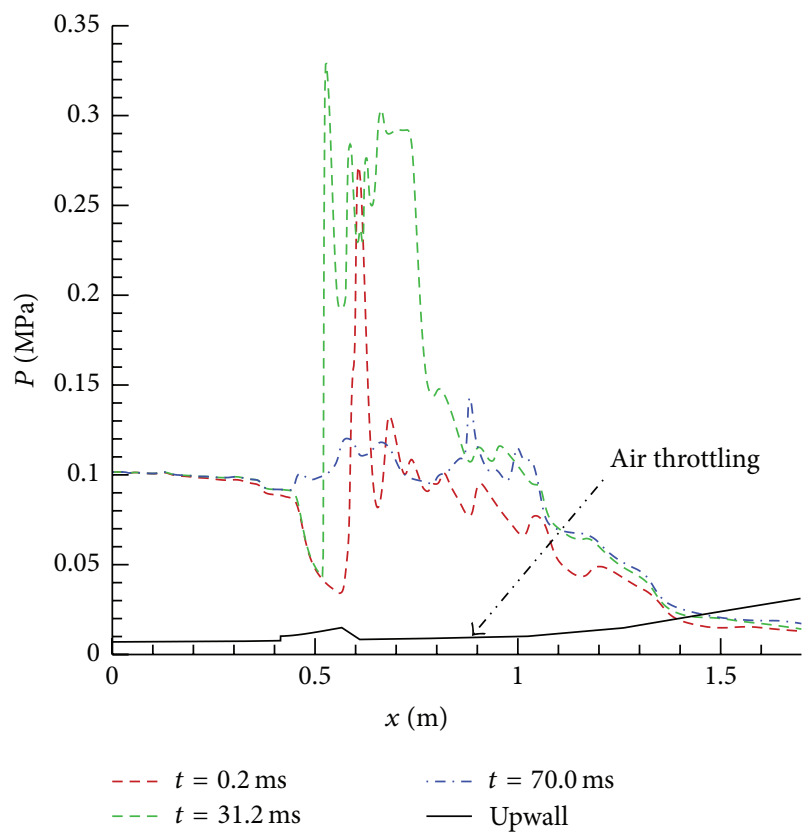

FIGURE 16: Wall pressure of the scramjet combustor with and without air throttling at $t=70.0 \mathrm{~ms}$.

throttling location of $875 \mathrm{~mm}$ was higher obviously than that of the case with air throttling location of $745 \mathrm{~mm}$, there was only an oblique shock wave near the cavity ramp in the flow field with air throttling location of $745 \mathrm{~mm}$, and so the wall pressure of the case with air throttling located at $745 \mathrm{~mm}$ was almost equal to that of the case without air throttling except for the position of the cavity ramp. The mass averaged velocity of the scramjet combustor for the three cases was shown in Figure 17. The mass averaged velocity of the case with air throttling location of $875 \mathrm{~mm}$ was lower obviously than that of the other two cases. So the velocity was lower and the pressure was higher when there was a shock train in the flow field. From the above discussion, we know when pilot $\mathrm{H}_{2}$ was injected into the flow, the velocity of the combustor with air throttling location of $875 \mathrm{~mm}$ was lower than that of the case with air throttling location of $745 \mathrm{~mm}$ and the pressure of the combustor with air throttling location of $875 \mathrm{~mm}$ was higher than that of the case with air throttling location of $745 \mathrm{~mm}$. The lower velocity and higher pressure of the flow field were helpful to fuel/air mixture ignition, so the combustion of air throttling location of $875 \mathrm{~mm}$ stabilized successfully. We believed that if pilot $\mathrm{H}_{2}$ was injected into flow field at $t=$ $31.2 \mathrm{~ms}$, the combustion in the flow field with air throttling location of $745 \mathrm{~mm}$ would stabilize successfully. If pilot $\mathrm{H}_{2}$ was injected into flow field at $t=80.0 \mathrm{~ms}$, the combustion in the flow field with air throttling location of $875 \mathrm{~mm}$ would not stabilize successfully. It was important to choose the location and time sequence of air throttling for fuel ignition and flame stabilization.

\section{Conclusion}

The effect of air throttling on flame stabilization of an ethylene fueled scramjet combustor was investigated by CFD and 


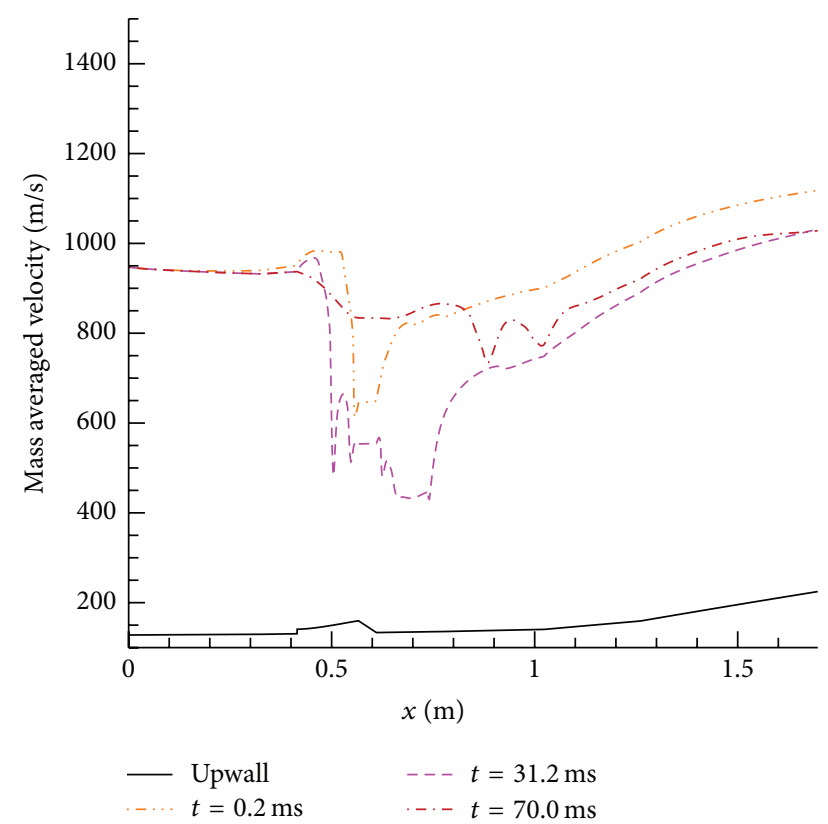

FIGURE 17: Mass averaged velocity of the scramjet combustor with and without air throttling at $t=70.0 \mathrm{~ms}$.

experiment. Our results indicated that air throttling had a great effect on the thermodynamic parameters in the flow field. Compared with the combustor without air throttling, the flow field with air throttling had a lower velocity and higher pressure, temperature, and vortices intensity. Air throttling was an effective way to achieve flame stabilization, the combustion in the combustor without air throttling was nearly blowout, and only a small portion of the flame was anchored in the rearward step of the cavity and in the boundary layer of the up wall. With air throttling, an intensive combustion in the whole cavity and wall boundary layer can be achieved; the shock train could be seen clearly in the isolator because of the pressure increased in the combustor. It was important to choose the location and time sequence of air throttling for fuel ignition and flame stabilization.

\section{Conflict of Interests}

The authors declare there is no conflict of interests regarding the publication of this paper.

\section{Acknowledgments}

The project was supported by the National Natural Science Foundation of China (no. 51376194, no. 51376193, and no. $51406222)$.

\section{References}

[1] T. Mathur, K. C. Lin, P. Kennedy et al., "Liquid JP-7 combustion in a scramjet combustor," AIAA 2000-3581, American Institute of Aeronautics and Astronautics, 2000.
[2] J. Li, F. H. Ma, V. Yang, K.-C. Lin, and T. Jackson, "Control and optimization of ignition transient of scramjet engine using air throttling," in Proceedings of the 44th Aiaa Aerospace Sciences Meeting and Exhibit, AIAA 2006-1028, Reno, Nev, USA, January 2006.

[3] J.-Y. Choi, J. Noh, J.-R. Byun, J.-S. Lim, K. Togai, and V. Yang, "Numerical investigation of combustion/shock-train interactions in a dual-mode scramjet engine," in Proceedings of the 17th AIAA International Space Planes and Hypersonic Systems and Technologies Conference, San Francisco, Calif, USA, April 2011.

[4] W. Bao, J. Hu, Y. Zong et al., "Ignition characteristics of a liquidkerosene-fueled scramjet during air throttling combined with a gas generator," Journal of Aerospace Engineering, vol. 27, no. 5, 2014.

[5] V. Yang, J. Li, J. Y. Choi et al., "Ignition transient in an ethylene fueled scramjet engine with air throttling. Part I: non-reacting flow development and mixing," AIAA 2010-409, American Institute of Aeronautics and Astronautics, 2010.

[6] V. Yang, J. Li, J. Y. Choi, L. Zhang, and K.-C. Lin, "Ignition transient in an ethylene fueled scramjet engine with air throttling. Part II: ignition and flame development," in Proceedings of the 48th AIAA Aerospace Sciences Meeting Including the New Horizons Forum and Aerospace Exposition, AIAA 2010-410, Orlando, Fla, USA, January 2010.

[7] W. X. Deng, J. L. Le, S. H. Yang et al., "Ethylene fueled scramjet combustion experiments," Modern Applied Science, vol. 7, no. 5, pp. 51-59, 2013.

[8] W. Z. Zhang, J. L. Le, S. H. Yang, W. Cheng, W. Deng, and H. Zhou, "Experimental research on hydrogen and hydrocarbon fueled ignition for scramjet at $\mathrm{Ma}=4$," Modern Applied Science, vol. 7, no. 3, pp. 56-63, 2013.

[9] J. L. Le, S. H. Yang, W. X. Liu et al., "Massively parallel simulations of kerosene-fueled scramjet," AIAA 2005-3318, American Institute of Aeronautics and Astronautics, 2005.

[10] Z. H. Zheng and J. L. Le, "Massively parallel computation of three-dimensional scramjet combustor," in Shock Waves: Proceedings of the 24th International Symposium on Shock Waves Beijing, China July 11-16, 2004, pp. 897-902, Springer, Berlin, Germany, 2005.

[11] D. R. Eklun, R. A. Baurle, and M. R. Gruber, "Numerical study of a scramjet combustor fueled by an aerodynamic ramp injector in dual-mode combustion," AIAA 2001-0379, American Institute of Aeronautics and Astronautics, 2001. 

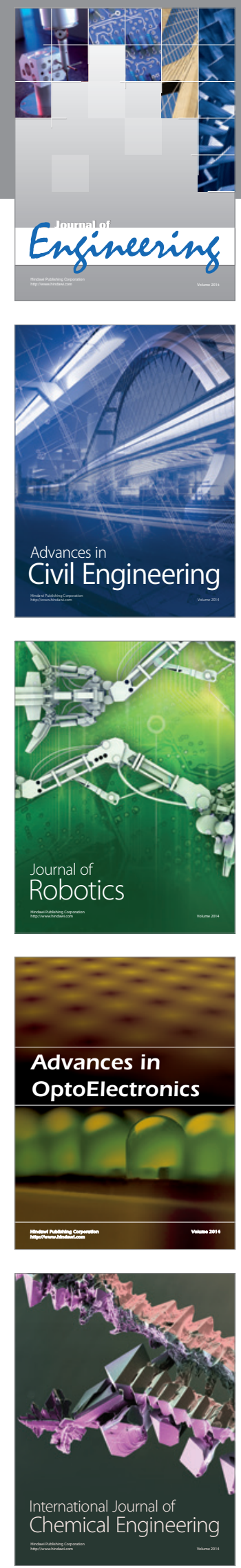

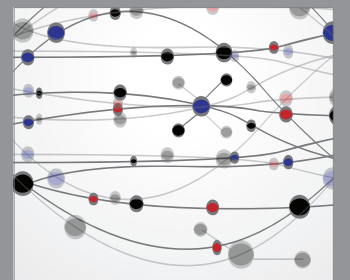

The Scientific World Journal
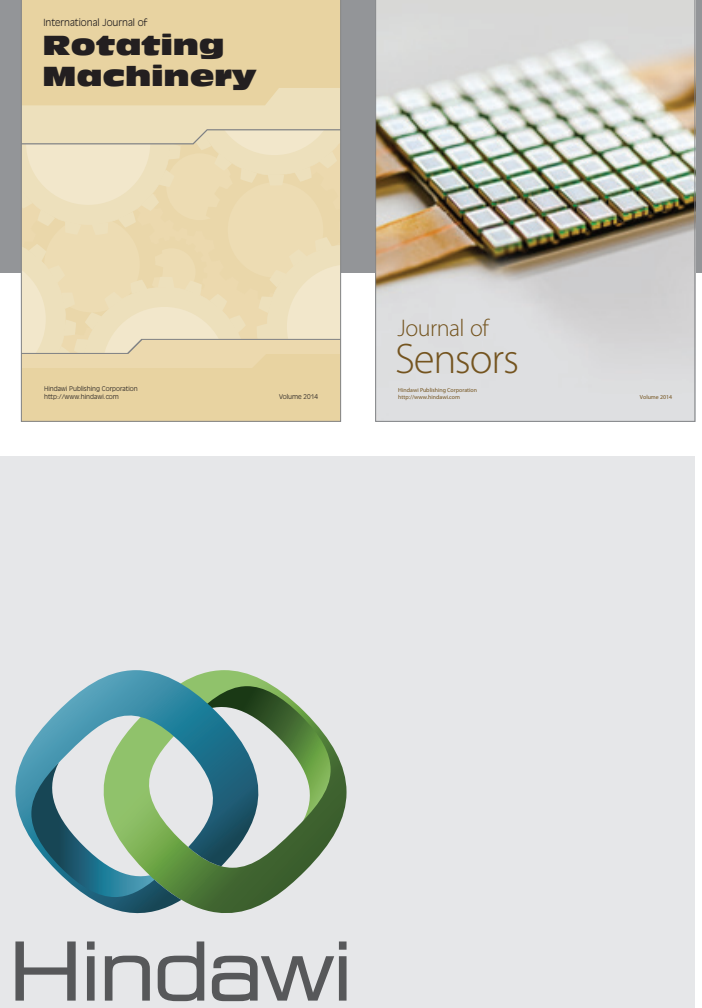

Submit your manuscripts at http://www.hindawi.com
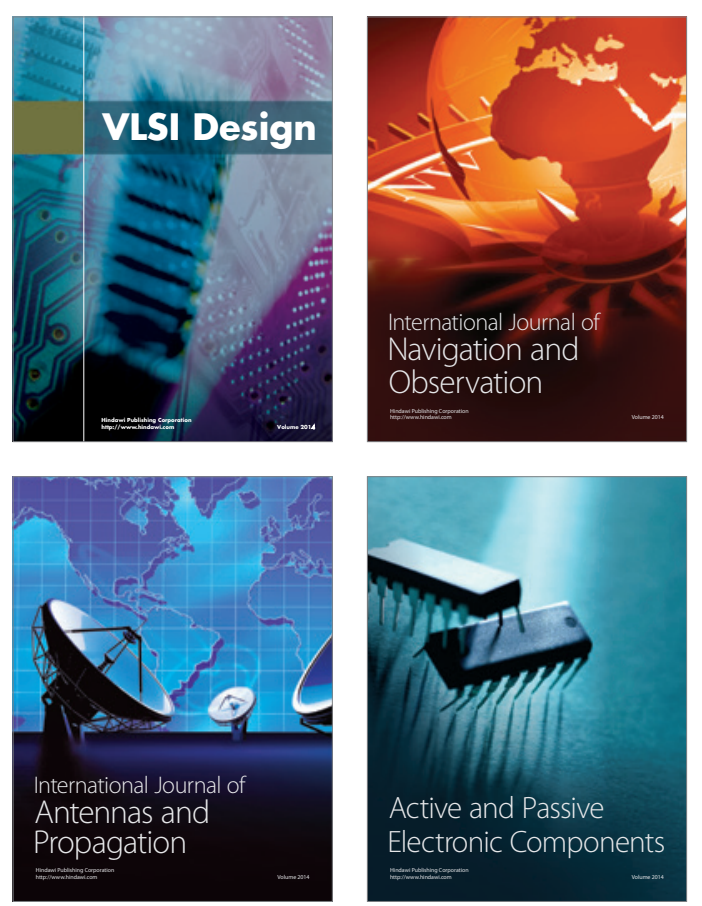
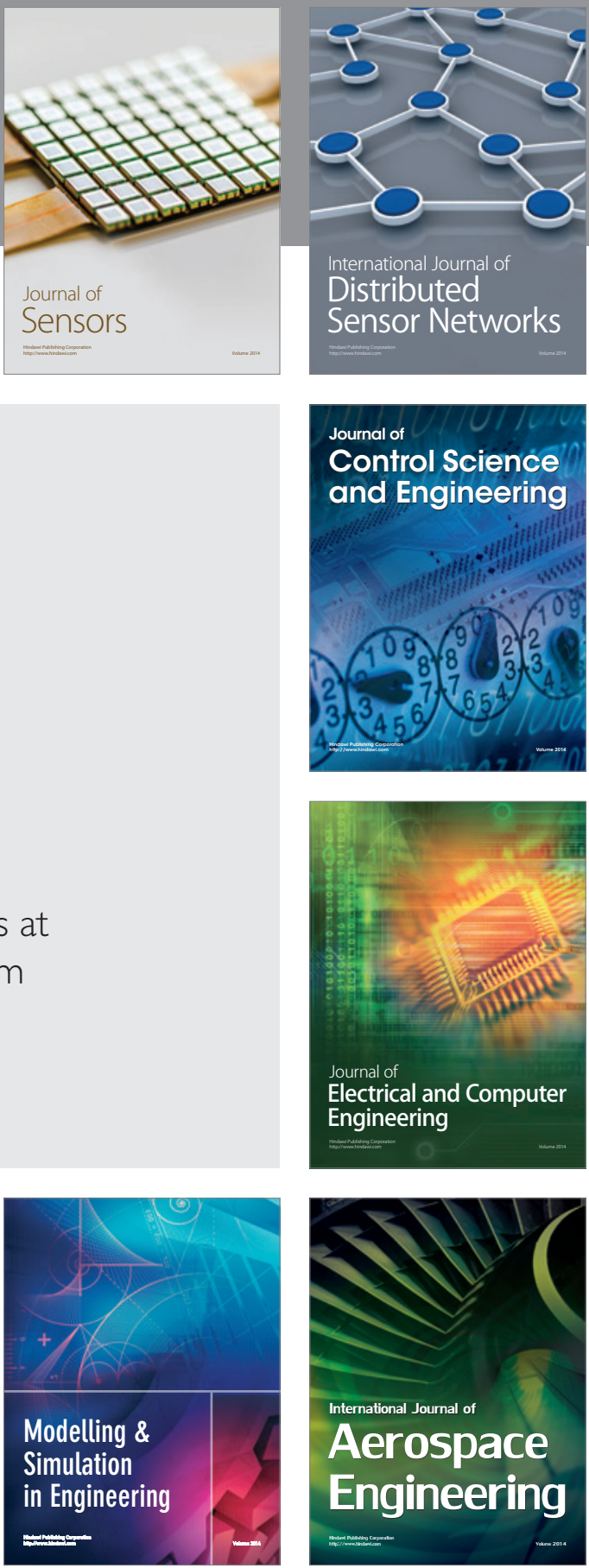

Journal of

Control Science

and Engineering
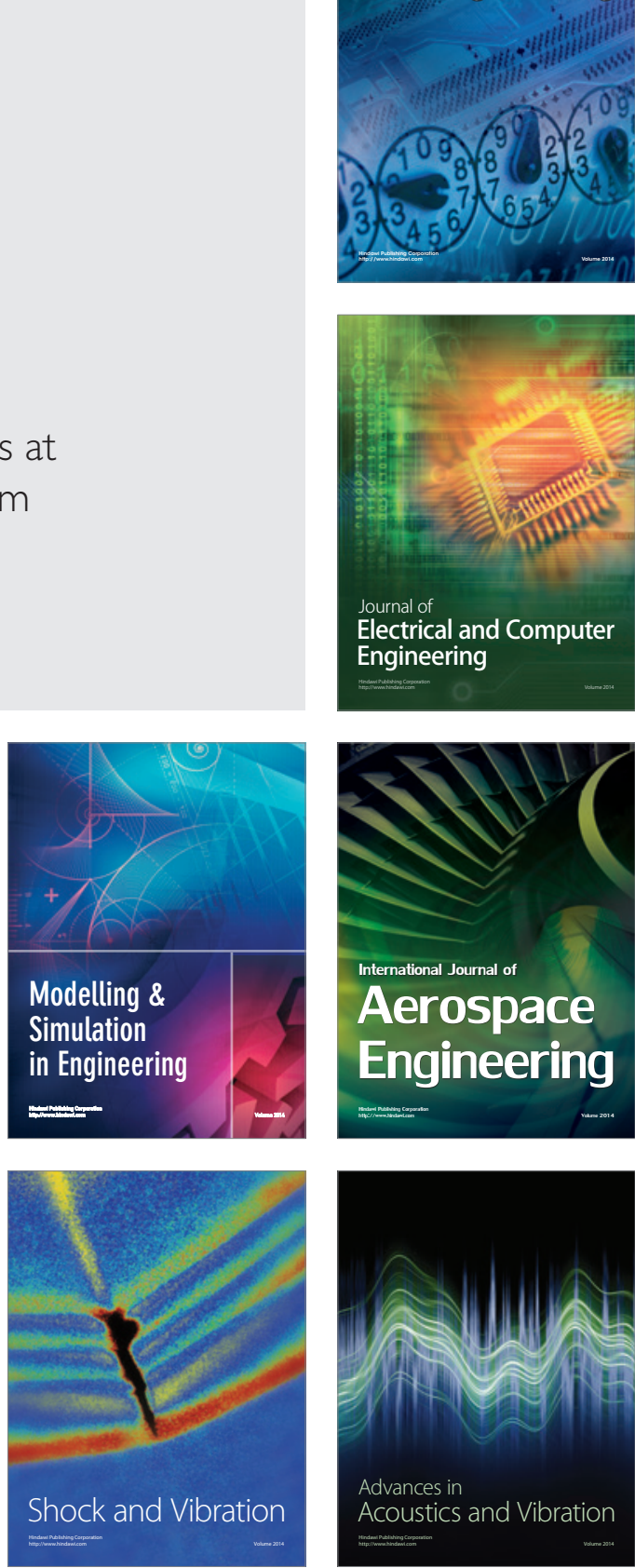